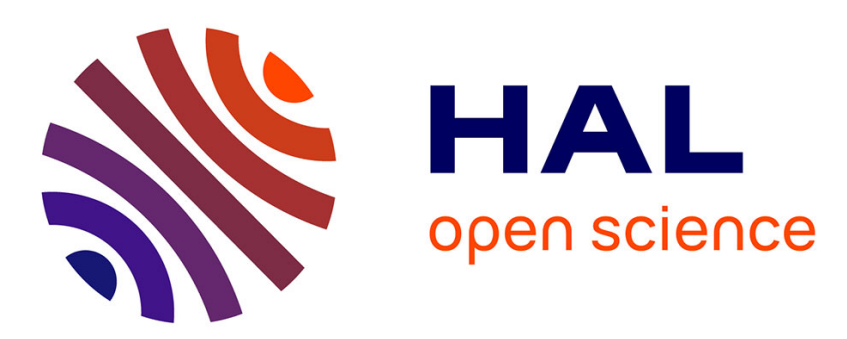

\title{
Experimental Evidence on Inequity Aversion and Self-Selection between Incentive Contracts
}

\author{
Sabrina Teyssier
}

\section{To cite this version:}

Sabrina Teyssier. Experimental Evidence on Inequity Aversion and Self-Selection between Incentive Contracts. 2008. halshs-00303727

\section{HAL Id: halshs-00303727 https://shs.hal.science/halshs-00303727}

Submitted on 22 Jul 2008

HAL is a multi-disciplinary open access archive for the deposit and dissemination of scientific research documents, whether they are published or not. The documents may come from teaching and research institutions in France or abroad, or from public or private research centers.
L'archive ouverte pluridisciplinaire $\mathbf{H A L}$, est destinée au dépôt et à la diffusion de documents scientifiques de niveau recherche, publiés ou non, émanant des établissements d'enseignement et de recherche français ou étrangers, des laboratoires publics ou privés. 


\title{
DOCUMENTS DE TRAVAIL - WORKING PAPERS
}

\author{
W.P. 08-21
}

Experimental Evidence on Inequity Aversion and

Self-Selection between Incentive Contracts

\section{Sabrina Teyssier}

Mai 2008

GATE Groupe d'Analyse et de Théorie Économique UMR 5824 du CNRS

93 chemin des Mouilles - 69130 Écully - France

B.P. $167-69131$ Écully Cedex

Tél. +33 (0)4 72866060 - Fax +33 (0)4 72866090

Messagerie électronique gate@gate.cnrs.fr

Serveur Web : www.gate.cnrs.fr 


\title{
Experimental Evidence on Inequity Aversion and Self-Selection between Incentive Contracts*
}

\author{
Sabrina Teyssier ${ }^{\dagger}$
}

May 2008

\begin{abstract}
This paper reports on the results of an experiment testing whether the agents selfselect between a competitive payment scheme and a revenue-sharing scheme depending on their inequity aversion. Average efficiency should be increased when these payment schemes are endogenously chosen by agents. We show that the choice of the competition is negatively affected by disadvantageous inequity aversion and risk aversion. In the second half of the experiment, the effect of individual preferences is indirect through the effect of past results. The self-selection of agents increases the efficiency of the competitive scheme but not that of the revenue-sharing scheme, due to a heterogeneity of behaviors.
\end{abstract}

JEL classification: C92, D63, J31, J33, M52

Keywords: performance pay, incentives, self-selection, inequity aversion, competition, revenue-sharing scheme

*I am grateful to Christian Belzil, Martin Dufwenberg, Dirk Engelmann, Romain Zeiliger and especially to Marie-Claire Villeval. I am also grateful to participants at the GATE research seminars, the EWEBE meeting in Lyon and the SOLE meeting in New-York. Financial support from the French Agency of Research - project "Experiments on Motivation, Incentives and Rationality" (ANR-EMIR) is gratefully acknowledged.

${ }^{\dagger}$ GATE, University of Lyon, CNRS, ENS-LSH, France. Email: teyssier@gate.cnrs.fr. 


\section{Introduction}

Group performance payment schemes provide incentives to workers without necessitating a precise measure of individual performance. The cost of performance monitoring is then limited when individual output is hardly measurable. Different types of group performance schemes coexist on the market (O'Dell and McAdams, 1987, Prendergast, 1999, Pfeffer, 2007). In fact, depending on the distribution of payoffs within group, group performance payment schemes can either be characterized by a competitive or by a cooperative structure of payments. ${ }^{1}$ We hypothesize that this diversity matches the diversity of worker's types. ${ }^{2}$ As workers' type is hardly identifiable, it may be more efficient to let workers self-select their payment scheme.

The matching employer-employees does not only depend on skills but also on gender, risk aversion or intrinsic motivation. ${ }^{3}$ Because a self-selection of agents by social preferences is only suggested by previous studies, the aim of this paper is to test directly whether agents' inequity aversion, in the sense of Fehr and Schmidt (1999), drives agents' choice of payment schemes. ${ }^{4}$ The consequences of self-selection on the efficiency of payment schemes is then inferred. As inequity aversion of workers is hardly observable and due to the endogeneity biais in business data, we conduct a laboratory experiment. It allows for a measure of inequity aversion degrees of all the agents that leads to a direct test of the influence of each agent's inequity aversion on his choice and effort decisions. The difference between the competitive structure and the revenue-sharing structure only concerns the distribution of payoffs inside a group of employees.

Previous studies have shown that agents differ in their social preferences and realize a higher expected utility when groups are homogeneous under a particular payment scheme adapted to these preferences (Burlando and Guala, 2005, Carpenter and Seki,

\footnotetext{
${ }^{1}$ For theoretical work, see the seminal papers of Lazear and Rosen (1981) and Moldovanu and Sela (2001) on the analysis of competition and see Holmstrom (1982) on the analysis of revenue-sharing scheme.

${ }^{2}$ The mismatch between workers and jobs may explain disatisafaction at the workplace. See Clark and Oswald (1996) for evidence of the relation between job satistation and comparison of incomes and see Pfeffer (2007).

${ }^{3}$ Empirical studies emphasized the existence of a self-selection of agents by their skill levels (Lazear, 2000, Hamilton, Nickerson and Owan, 2003, Chiappori and Salanié, 2003, Dohmen and Falk, 2006). However, other individual characteristics influence the choice of agents between different payment schemes such as gender (Niederle and Vesterlund, 2007, Datta Gupta, Poulsen and Villeval, 2005), risk aversion (Bellemare and Shearer, 2006, Bonin et al., 2006, Cadsby, Song and Tapon, 2006, Dohmen and Falk, 2006, Eriksson, Teyssier and Villeval, 2008, Grund and Sliwka, 2006) or intrinsic motivation (Goddeeris, 1988).

${ }^{4}$ Bandiera, Barankay and Rasul (2005), Lazear, Malmendier and Weber (2006) and Keser and Montmarquette (2007) suggest a sorting of agents by payment scheme based on agents' social preferences but do not evaluate agents' social preferences.
} 
2005, Gächter and Thöni, 2005, Fischbacher and Gächter, 2006, Dannenberg, Riechmann, Sturm and Vogt, 2007, Torgler, Schaffner, Frey and Schmidt, 2008). Since competitive and revenue-sharing schemes differ in terms of the distribution of payoffs, workers may increase their expected utility under a particular payment scheme depending on their social preferences. They may therefore self-select the firm according to the payment scheme in use. Such a self-selection of agents can increase the market efficiency through both an increased effort level and higher payoffs of workers.

The existence of a separating equilibrium based on agents' social preferences has been demonstrated theoretically. Even without any complementarity between employees of the same ability, Cabrales and Calvo-Armengol (2008) prove the existence of a segregation of workers in different firms depending on their ability level when they are affected by the situation of agents sufficiently close to them. Kosfeld and von Siemens (2007) underline, under the assumption of perfectly observable agents' performance, that a separating equilibrium exists when agents differ in their level of reciprocity. Selfish agents prefer to be compensated by a payment scheme based on their absolute individual performance whereas reciprocal agents prefer a group payment by maintaining cooperation as an equilibrium. At the equilibrium, two types of organizations coexist on the market. In Teyssier (2007), allowing the agents to choose between competitive schemes and a revenue-sharing scheme leads to the existence of a separating equilibrium in terms of inequity aversion. Selfish agents prefer the most competitive scheme whereas inequity averse agents feel better off under the revenue-sharing scheme.

Few empirical studies analyzing agents' self-selection measure also their social preferences. ${ }^{5}$ The only studies known at the moment are experimental studies. Dohmen and Falk (2006) analyze agents' self-selection between a fixed wage and a tournament or a revenue-sharing scheme based on their preferences which are measured through a sequential trust game. They find that reciprocal agents prefer to avoid the tournament but no effect is observed regarding the choice of the revenue-sharing scheme. Their experimental design considers agents of different reciprocity levels but is not based on equity considerations. The laboratory experiment conducted by Cabrales, Miniaci, Piovesan and Ponti (2008) assumes a market in which each principal chooses to offer a contrat. The choice is

\footnotetext{
${ }^{5}$ The optimal choice of different contracts by a principal in a moral hazard context (bonus contracts, explicit incentive contracts, trust contracts) is shown to be affected by fairness concerns of the principal in the experiment conducted by Fehr, Klein and Schmidt (2007).
} 
made between two contracts that differ on the spread between agents' payoffs and also on the robustness of the equilibrium. They analyze which trade-off the agents make between inequality and strategic uncertainty of the contracts offered. They find that the strategic uncertainty is a stronger determinant of choices of contracts than social preferences.

Our laboratory experiment is designed to evaluate the "pure" impact of inequity aversion on both the choice of agents between two compensation schemes differing on the distribution of payoffs and their decision of effort. ${ }^{6}$ To capture the effect of inequality, we hold the efficiency constant in every case in both payment schemes. In contrast with the choice treatment, in the benchmark treatment, the payment schemes are exogenously imposed to the agents: half of the agents are compensated under a competitive structure and the other half under a revenue-sharing structure. The preferences of the agents were elicited in experimental sessions played one week before the game sessions in order to avoid influences between the measures of preferences and the decisions in the game. The strategic method (Selten, 1967) has been used. We elicited advantageous inequity aversion by means of a modified dictator game and disadvantageous inequity aversion by means of an ultimatum game. Risk attitude was elicited using the Holt and Laury's procedure (2002).

The theory predicts that agents with sufficiently high advantageous or disadvantageous inequity aversion prefer to be compensated by the revenue-sharing scheme. Allowing agents to choose should increase efficiency, in terms of average effort level and agents' payoffs. Our results show that individual preferences drive the agents' choices. Agents with high disadvantageous inequity aversion are less likely to choose the competition. Risk aversion also decreases the probability of choosing the competition. More precisely, the effect of preferences is indirect in the second half of the experiment through the significant effect of past results. The consequence on efficiency is twofold. On the one hand, the possibility to self-select increases the average effort level under the competition but not under the revenue-sharing scheme. On the other hand, the agents maximize their payoffs when choosing according to their preferences. The self-selection of agents is efficient under the competition but imperfect under the revenue-sharing scheme due to a heterogeneity of effort behaviors.

The paper is organized as follows. We present in section 2 the general model and the experimental design. Results are analyzed in section 3. Section 4 concludes.

\footnotetext{
${ }^{6} \mathrm{As}$ it is assumed that the individual effort level is not perfectly observable, under the competitive scheme, the agents' effort decision affects their probability to obtain the higher or the lower payoff.
} 


\section{Model and experimental design}

The theoretical predictions are based on the model developed in Teyssier (2007). We precise here the predictions associated with the design and the parameters of the experiment.

\subsection{Model}

Consider risk neutral agents with identical abilities. The agents are heterogeneous in their concern for inequality (Fehr and Schmidt, 1999). We suppose them being of two types, $\theta \in\left\{\theta_{S}, \theta_{A}\right\}$. Some are exclusively interested in their own payoff, type $\theta_{S}$, and the others are affected by the payoff of agents closed to them, type $\theta_{A}$. As in the Fehr and Schmidt's model, the utility function is the following for player $i$ :

$$
U_{i}\left(x_{i}, x_{j}\right)=x_{i}-\alpha_{i} \max \left\{x_{j}-x_{i}, 0\right\}-\beta_{i} \max \left\{x_{i}-x_{j}, 0\right\} \quad i \neq j
$$

where $x_{i}$ and $x_{j}$ represent the monetary payoffs of agents $i$ and $j$. Inequity averse individuals are assumed to be averse to both advantageous inequality $\left(\beta_{i}\right)$ and disadvantageous inequality $\left(\alpha_{i}\right)$. Moreover, earning less than the other agent in the group has a bigger negative impact on utility than earning more, $\alpha_{i} \geq \beta_{i}$ with $0 \leq \beta_{i}<1$. The proportion of agents of type $\theta_{A}, \alpha \neq 0$ and $\alpha \geq \beta$ with $0 \leq \beta<1$, is $\rho$. $(1-\rho)$ is then the proportion of agents of type $\theta_{S}, \alpha=\beta=0$.

The game consists of two stages. In the first stage, two compensation modes differing on the level of competition are proposed to all agents. Each agent must choose the one he prefers. In the second stage, each agent is matched with another agent who has chosen the same payment structure as him in the first stage and they form a group for five repeated periods. The two agents of each group decide simultaneously of a level of effort, $e_{i}$ for the agents $i$. The cost of effort function is convex in the effort level, $c\left(e_{i}\right)=\frac{e_{i}^{1.5}}{20}{ }^{7}$ The total production of each group is equal to the sum of the effort levels of the two agents in the group, $e_{i}+e_{j}$. The group production is supposed perfectly observable but the individual output cannot be observed with certainty.

Due to the uncertainty on individual effort levels, the two compensation schemes proposed are based on the agents' relative performance. In the contest, rewarded prizes are

\footnotetext{
${ }^{7}$ The parameters of the cost of effort function have been chosen to obtain comparable payoffs in different cases.
} 
endogenous to the group joint output to avoid collusion. The winner's prize is a share $\tau$, $\tau \in\left[\frac{1}{2}, 1\right]$, of the total production of the group. It writtes $W\left(e_{i}, e_{j}\right)=\tau \cdot\left(e_{i}+e_{j}\right)+F$, with $F$, a fixed payment given to every agent. The loser receives $L\left(e_{i}, e_{j}\right)=(1-\tau) \cdot\left(e_{i}+e_{j}\right)+F$. The competitiveness of the contest increases with $\tau$ by increasing the spread between the contestants' prizes, for given levels of effort. The two compensation schemes are based on the same structure but differ on the value of the share of the group output rewarded to the winner of the contest, $\tau$. As the individual output is not perfectly observable, the winner of the contest is not the agent with the highest effort level with certainty. According to the Tullock model (1980), each agent's probability of winning depends on the ratio between his own production and the group joint production:

$$
\operatorname{Pr}\left(p_{i}\left(e_{i}, e_{j}\right)=W\left(e_{i}, e_{j}\right)\right)=\frac{e_{i}}{e_{i}+e_{j}}
$$

The probability of winning the prize $W\left(e_{i}, e_{j}\right)$ is increasing in the agent's effort level.

Among the two compensation modes proposed, one is competitive while the other one is not. The competitive structure is characterized by a share of the group output given to the winner of the contest equal to $0.75, \tau=0.75$. The other structure is a revenue-sharing payment scheme where $\tau=0.5$. The joint production is in this case equally divided between the group members; the winner and the loser earn exactly the same prize. The revenuesharing structure is equivalent to a public goods game in the sense that the whole group output is equally shared between the agents regardless of their personal investment. Under both payment schemes, a positive fixed payment, $F=14$, is awarded to all the subjects. $F$ avoids any negative payoff to the subjects, even to the loser of the competition. ${ }^{8}$

In the second stage of the game, the agents decide on a level of effort. For the sake of simplification, they are allowed to choose between two levels of effort. ${ }^{9}$ Following the model with continuous effort levels developed in Teyssier (2007), the two levels of effort available in the experiment are the Nash equilibria of selfish agents under each contest structure. When $\tau=0.5$, selfish agents have a dominant strategy that is $e_{S}^{R S *}=44.44$. We call it effort $e_{L}$. The Nash equilibrium is higher under the competitive scheme, $e_{S}^{C *}=100$,

\footnotetext{
${ }^{8}$ Loss aversion may play a role on agents' behavior when they respond to incentive payment schemes (Kahneman and Tversky, 1984, Kahneman, Knetsch and Thaler, 1991).

${ }^{9}$ The complexity of the game in the computation of payoffs when effort levels are continuous is limited here by letting subjects the choice between only two effort levels. This design has been chosen to limit random behaviors. Moreover, to limit the effort level space to only two levels does not change the predictions.
} 
called effort $e_{H}$.

Two situations exist under the competitive structure: either the agent $i$ wins the contest (he is in the High situation), or he loses it (he is in the Low situation). According to equation (2), if agent $i$ plays the high effort level, $B$, when he faces an agent $j$ who plays the low effort level, $e_{L}$, his probability to be in the high situation is $70 \%$ whereas it is about $30 \%$ when he plays $e_{L}$ and the agent $j$ plays $e_{H}$. When both subjects in the group play the same effort level, i.e. either both subjects play $e_{L}$ or both play $e_{H}$, their probability to be in the high situation is $50 \%$. This differentiation is useful only for the competitive structure but in order to keep the same presentation under both payment schemes in the experiment, we construct a high situation and a low situation under the revenue-sharing structure as well. We have been careful that subjects' payoffs are always higher when they both exert $e_{H}$ than when they both exert $e_{L}$. The two agents in the same group earn the same net payoff when they play the same effort level, whatever the situation.

Figure 1 presents agents' net payoffs under each payment scheme and for every combination of effort levels. ${ }^{10}$

High situation

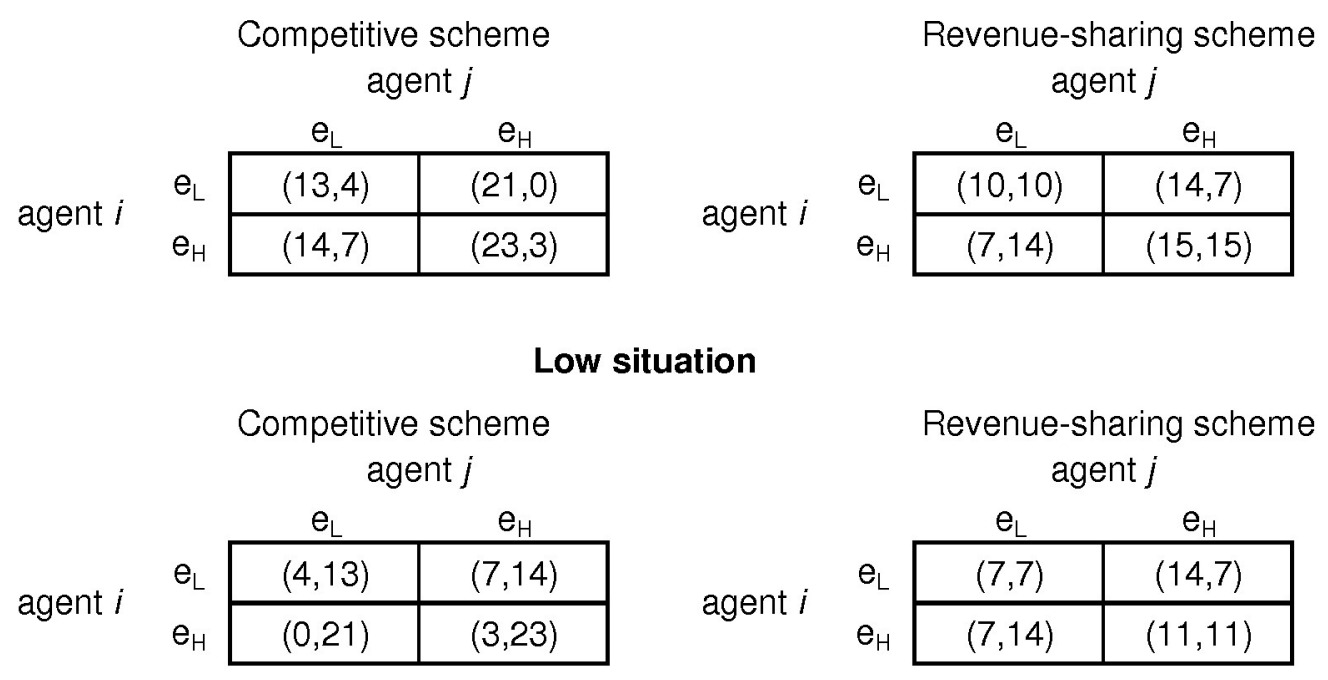

Figure 1: Payoff matrices

\footnotetext{
${ }^{10} \mathrm{We}$ assume that agents compare their payoffs once the cost of effort deduced. On the business place, we think that agents working in the same group are able to evaluate the cost of effort of the other agent in the group. Then, it seems more realistic that agents compare their net payoffs instead of their payoff before the deduction of costs of effort. Moreover, when they apply their model to explain experimental evidence in public goods games, Fehr and Schmidt (1999) compare net payoffs of agents. In a context of a public goods game, the payoffs considered are the revenue of the public good minus the individual contribution to the public good. Experimental results observed in public goods games support the comparison between net payoffs. Then, it appears in the continuation of the Fehr and Schmidt's model to compare net payoffs of agents (see also Akerlof and Yellen, 1990, for some evidence of the fair wage-effort hypothesis).
} 
The difference between the two payment schemes resides in the ex post inequality between payoffs. It appears clearly that the payoffs are dramatically more unequal under the competitive payment scheme than under the revenue-sharing one. To focus on the effect of inequality between ex post net payoffs, we hold some characteristics constant between the two payment schemes. First, the parameters lead to equivalent expected net payoffs under both payment schemes when the subjects play the same effort level: $x_{i}^{R S}\left(e_{L}, e_{L}\right)=x_{i}^{C}\left(e_{L}, e_{L}\right)=8.5$ and $x_{i}^{R S}\left(e_{H}, e_{H}\right)=x_{i}^{C}\left(e_{H}, e_{H}\right)=13$. Consequently, the Pareto optimum under both payment schemes corresponds to the situation in which both agents exert $e_{H}$. Second, the social welfare, given by the sum of the expected utilities of subject $i$ and subject $j$, for every possible combination of effort levels, is identical under both the competitive scheme and the revenue-sharing scheme.

\subsection{Predictions}

We want to test the effect of inequity aversion on the choice of payment scheme and the consequences of this choice. The predictions are derived by backward induction. We solve first the second stage of the game. Inequity aversion degrees of agents, advantageous and disadvantageous, drive their equilibrium effort decisions under both payment schemes. This influence leads to a different choice of payment schemes depending on agents' inequity aversion degrees. The computation of the results are provided in the appendix.

For simplification, we use the following notations of the theoretical thresholds of disadvantageous inequity aversion, with $\rho_{C}$, the proportion of inequity averse agents under the competition and $\rho_{R S}$, the proportion of inequity averse agents under the revenue-sharing

scheme. Inquity averse agents with a disadvantageous inequity aversion lower or equal to $\alpha^{C}(\beta)$ play the $e_{H}$ effort level under the competition. There exist two equilibrium effort levels under the revenue-sharing scheme for agents with $\alpha$ higher or equal to $\alpha^{R S}$. Finally, agents with $\alpha$ higher or equal to $\alpha^{S}(\beta)$ prefer to be compensated under the revenue-sharing scheme than under the competition. Agents with $\beta \geq 0.15$ choose also the revenue-sharing scheme.

$$
\alpha^{C}(\beta)=\frac{\left(1.8+2.7 \rho_{C}\right)-\beta\left(3.7+1.8 \rho_{C}\right)}{5.1+0.4 \rho_{C}}
$$




$$
\begin{gathered}
\alpha^{R S}=\frac{6 \rho_{R S}-1.5}{7\left(1-\rho_{R S}\right)} \\
\alpha^{S}(\beta)=\frac{2.7-6.3 \beta}{4.9}
\end{gathered}
$$

The hypotheses are then the following.

Hypothesis 1. Agents with sufficiently high advantageous or disadvantageous inequity aversion prefer to be compensated by the revenue-sharing scheme instead of the competitive scheme.

Table 1 presents the choice of payment scheme in function of agents' advantageous and

\begin{tabular}{|c|c|c|}
\hline \multicolumn{2}{|c|}{ Social preferences } & Choice \\
\hline \multicolumn{2}{|c|}{ Selfish agent $(\alpha=\beta=0)$} & Competition \\
\hline \multicolumn{3}{|c|}{ Inequity averse agent } \\
\hline \multirow[t]{2}{*}{$\alpha \leq\left.\alpha^{\mathrm{C}}(\beta)\right|_{p \mathrm{C}=0}$} & $\begin{array}{l}\beta<0.15 \text { and } \\
\alpha<\alpha^{S}(\beta)\end{array}$ & Competition \\
\hline & $\begin{array}{l}\beta \geq 0.15 \text { and } \\
\alpha \geq \alpha^{S}(\beta)\end{array}$ & Revenue-sharing \\
\hline \multirow[t]{3}{*}{$\alpha>\left.\alpha^{\mathrm{c}}(\beta)\right|_{p \mathrm{C}=0}$} & $\begin{array}{l}\beta<0.15 \text { and } \\
\alpha<\alpha^{S}(\beta)\end{array}$ & Competition \\
\hline & $\begin{array}{l}\beta<0.15 \text { and } \\
\alpha \geq \alpha^{S}(\beta)\end{array}$ & Revenue-sharing \\
\hline & $\begin{array}{l}\beta \geq 0.15 \text { and } \\
\alpha \geq \alpha^{S}(\beta)\end{array}$ & Revenue-sharing \\
\hline
\end{tabular}
disadvantageous inequity aversion degrees.

Table 1: Choice of payment scheme (stage 1)

Selfish agents and inequity averse agents with both low advantageous and low disadvantageous inequity aversion prefer to be compensated under the competition while inequity averse agents with sufficiently high advantageous or disadvantageous inequity aversion prefer the revenue-sharing scheme.

Hypothesis 2. The efficiency of the game, in terms of average effort level and agents' payoffs, increases when self-selection is allowed. 
Equilibrium effort levels of agents under both payment schemes, exogenous and endogenous, are presented in table 2. Agents' payoffs can be deduced reminding that the Pareto optimum is reached when both agents play the high effort level.

\begin{tabular}{|c|c|c|c|c|c|}
\hline \multirow{2}{*}{\multicolumn{2}{|c|}{ Social preferences }} & \multicolumn{2}{|c|}{ Payment schemes imposed } & \multicolumn{2}{|c|}{ Payment schemes chosen } \\
\hline & & Competition & Revenue-sharing & Competition & Revenue-sharing \\
\hline \multicolumn{6}{|c|}{ Selfish agent $(\alpha=\beta=0)$} \\
\hline \multicolumn{2}{|c|}{$\begin{array}{l}\text { if } \mid \mathrm{A} \text { agents with } \\
\beta<0,15 \text { or } \alpha>\alpha^{\mathrm{RS}}\end{array}$} & $e_{H}$ & $e_{L}$ & $e_{H}$ & - \\
\hline \multicolumn{2}{|c|}{$\begin{array}{l}\text { if } \mid A \text { agents with } \\
\beta \geq 0,15 \text { and } \alpha \leq \alpha^{R S}\end{array}$} & $e_{H}$ & $e_{L}$ and $e_{H}^{(1)}$ & $e_{H}$ & - \\
\hline \multicolumn{6}{|c|}{ Inequity averse agent } \\
\hline \multirow[t]{2}{*}{$\alpha \leq\left.\alpha^{\mathrm{C}}(\beta)\right|_{\rho \mathrm{C}=0}$} & $\begin{array}{l}\beta<0.15 \text { and } \\
\alpha<\alpha^{S}(\beta)\end{array}$ & $e_{H}$ & $e_{L}$ & $\mathrm{e}_{\mathrm{H}}$ & - \\
\hline & $\begin{array}{l}\beta \geq 0.15 \text { and } \\
\alpha<\alpha^{S}(\beta)\end{array}$ & $\mathrm{e}_{\mathrm{H}}$ & $\begin{array}{l}e_{L} \text { and } e_{H} \\
\text { if } \alpha \leq \alpha^{R S}\end{array}$ & - & $e_{\llcorner}$and $e_{H}^{(1)}$ \\
\hline \multirow[t]{3}{*}{$\alpha>\left.\alpha^{\mathrm{c}}(\beta)\right|_{\rho \mathrm{C}=0}$} & $\begin{array}{l}\beta<0.15 \text { and } \\
\alpha<\alpha^{\mathcal{S}}(\beta)\end{array}$ & $e_{L}$ & $e_{L}$ & $e_{H}$ & - \\
\hline & $\begin{array}{l}\beta<0.15 \text { and } \\
\alpha \geq \alpha^{S}(\beta)\end{array}$ & $e_{L}$ & $e_{\mathrm{L}}$ & - & $e_{L}$ \\
\hline & $\begin{array}{l}\beta \geq 0.15 \text { and } \\
\alpha \geq \alpha^{S}(\beta)\end{array}$ & $e_{L}$ & $\begin{array}{l}\mathrm{e}_{\mathrm{L}} \text { and } \mathrm{e}_{H} \\
\text { if } \alpha \leq \alpha^{\mathrm{RS}}\end{array}$ & - & $e_{L}$ and $e_{H}{ }^{(1)}$ \\
\hline
\end{tabular}

\footnotetext{
${ }^{(1)}$ the $e_{H}$ equilibrium corresponds to the high effort level played for the periods 1 to 4 but the low effort level played for the period 5. Indeed, selfish agents mimic inequity averse agents' behavior by playing the high effort level for the periods 1 to 4 but cheat at the last period. Inequity averse agents play the low effort level at the last period to guaranty that selfish agents choose the competition instead of the revenue-sharing scheme; it is the condition to observe a separating equilibrium.
}

Table 2: Effort level equilibrium under the two payment schemes (stage 2)

When payment schemes are exogenously imposed to the agents, we first note that under the competition, selfish agents and agents with both low advantageous and low disadvantageous inequity aversion play the high effort level while other agents play the low effort level. Under the revenue-sharing scheme, to play the low effort level or the high effort level are both equilibrium strategies of agents with sufficiently high advantageous inequity aversion without too high disadvantageous inequity aversion. Agents with other preferences always play the low effort level at the equilibrium.

When payment schemes are freely chosen by agents, all agents choosing the competition play the high effort level. Therefore, inequity preferences of agents under the competition should not drive their decision of effort in this case. Under the revenue-sharing scheme, 
each of the two effort levels are an equilibrium strategy for most of the agents who choose this payment scheme. Nevertheless, agents with low advantageous inequity aversion but high disadvantageous inequity aversion choose the revenue-sharing scheme as well but only play the low effort level at the equilibrium.

The hypothesis of a higher efficiency when payment schemes are endogenously chosen is then only due to the increase of the average effort level under the competition. The average effort level under the revenue-sharing scheme does not decrease when payment schemes are endogenously chosen. However, we are not able to know whether it should be constant or increased. Two reasons are proposed. On the one hand, the multiplicity of equilibria under this payment scheme may induce a coordination problem. On the other hand, for a specific range of inequity aversion degrees of agents, inequity averse agents always play the low effort level. The agents' payoffs should raise under the competition because the Pareto optimum can be more often reached.

\subsection{Experimental design}

In order to analyze the sources and the effects of self-selection on the efficiency of group incentives, we conducted two different treatments. Inequity aversion degrees have been elicited for all the participants.

\subsubsection{Two treatments}

In the Benchmark treatment, the subjects are informed on being paid either under the revenue-sharing scheme (mode $X)$ or under the competitive scheme (mode $Y$ ). They are allocated randomly to one of the two compensation modes for the whole experiment. The subjects do not know the proportion of subjects paid under each payment scheme but they know the existence of both. We have chosen to mix subjects being paid under both payment schemes in order to have the same environment as in the other treatment described below. The subjects are matched in pairs. The pairs are fixed for five periods, called a sequence. Nine sequences of five periods are played to allow the subjects to learn the game. The subjects are rematched at the end of every sequence. Each subject knows his own payoff and also his co-worker's payoff under each payment scheme at the end of every period. The subject decides on his level of effort by choosing between $e_{L}$ and $e_{H}$.

In the Choice treatment, the only difference with the benchmark treatment is that, at 
the beginning of every sequence, each subject chooses under which payment scheme he wants to be compensated. Once the subject has chosen his payment scheme, he is matched with someone who has done the same choice as him. ${ }^{11}$ The subject is free to move from one payment scheme to the other one without any cost at the beginning of each new sequence.

The rematching of subjects after five periods has been chosen for three reasons. The partner matching protocol for five periods allows first agents to learn implications of one payment scheme for a sufficiently high number of periods. Second, agents are in this manner able to evaluate the type of the agent they are matched with. Finally, the rematching after five periods leads to the observation of several choices of payment schemes by agents.

\subsubsection{Elicitation of preferences}

We used the strategy method (Selten, 1967).

Advantageous inequity aversion $(\beta)$ Subjects are asked to participate in a modified dictator game (Blanco, Engelmann and Normann, 2006). The game involves two roles: the dictator and the receiver. All subjects take their decisions under both roles before knowing the actual role they have been allocated for payment. At the end of the session, the computerized program allocates randomly a role to each subject and payoffs are determined accordingly. Half of the subjects are a dictator and the other half a receiver. All subjects are matched with a dictator and a receiver in each pair.

The rules of the game are the following. Dictators make a choice between two options regarding the distribution of a pie between himself and the receiver. 21 decisions are presented to the subjects. Receivers cannot decide on anything. The first option, option $a$, corresponds to the equal share for the dictator and the receiver. The distribution is $\left(x_{i}, x_{i}\right)$ with $x_{i}=\{0, \ldots, 20\}$. The second option, option $b$, is to keep 18 points for himself and to give 2 points to the receiver, distribution $(18,2)$. The 21 decisions are such that under the decision 11, the choice is made between the distribution $(10,10)$ and the distribution $(18,2)$; under the decision 21 , the choice is made between the distribution $(20,20)$ and the distribution $(18,2)$.

Before playing as the dictator, subjects take first their decision as the receiver. They are

\footnotetext{
${ }^{11}$ All the sessions are composed of an even number of subjects. In case of an uneven number of subjects choosing a payment scheme, one of them having chosen the revenue-sharing payment scheme is picked randomly and is affected to the competitive scheme. This particular subject is informed of this change before deciding on his effort level.
} 
asked to decide to play the game or to opt out for a fixed payment ( 5 points $^{12}$ ). This first step allows to give a strategic dimension to the dictator game. Indeed, the evaluation of $\beta$ is then more easily associable with behaviors in games with strategic interactions. ${ }^{13}$ All subjects know the rules of the game at the time they intake their decision in the receiver's role.

The advantageous inequity aversion of agents, $\beta$, is estimated through the choices of subjects when they intake their decisions in the dictator's role. It is calculated by the decision number at which the agent switches from option $b$ to option $a$, i.e. from the distribution $(18,2)$ to the equal distribution. The value of $\beta$ is determined by $U_{i}\left(x_{i}-0.5, x_{i}-0.5\right)=$ $U_{i}(18,2)$, with $x_{i}$ being the decision number of the first decision in which the agent chooses the option $a$. The value of $\beta$ is then defined below.

$$
\beta_{i}=\frac{18.5-x_{i}}{16}
$$

Selfish agents are expected to switch from option $b$ to option $a$ at the decision number 19. All agents switching before the decision 19 have a positive $\beta . \beta$ is negative for agents changing their choice after the decision 19.

Disadvantageous inequity aversion $(\alpha)$ Subjects are asked to participate in an ultimatum game (Blanco, Engelmann and Normann, 2006). The game involves two roles: the sender and the responder. All subjects take their decisions under both roles before knowing the actual role they have. At the end of the session, the computerized program allocates randomly a role to each subject and payoffs are determined accordingly. Half of the subjects are allocated to the sender's role and to the responder's role. All subjects are matched in pairs with a sender and a responder in each pair.

In the role of the sender, the subject receives an endowment of 20 points. He must decide on the distribution of this amount between himself and the responder, knowing that the responder can either accept or reject this share. If the responder accepts the distribution, this distribution is implemented but if he rejects it, both the sender and the

\footnotetext{
${ }^{12}$ Under the assumption that the dictators are selfish, the average payoff of the receiver is around 5 points.

${ }^{13}$ Fehr and Schmidt (1999) underline that the dictator game allows to measure $\beta$ but it is limited due to the non strategic character of such a game. Moreover, Lazear, Malmendier and Weber (2005) underline that agents' decisions in a dictator game are affected by the opportunity of choosing to play the game or to opt out
} 
responder earn nothing. Then, the responder must choose between two options for 21 decisions. The option $a$ is to accept the distribution and the option $b$ is to reject it. Each decision corresponds to a particular distribution. Under the decision 1, the choice is made between accepting the distribution $(20,0)$ and rejecting it; under the decision 11 , the choice is made between accepting the distribution $(10,10)$ and rejecting it.

The responder's decisions under the ultimatum game allows us to measure the degree of disadvantageous inequity aversion, $\alpha$, of the agents. The estimation of $\alpha$ is realized through the decisions of the responder by the decision number at which the agent switches from option $b$ to option $a$; i.e. for which distribution the subject changes from rejecting to accepting the distribution. It is then estimated through the decisions of the responder. The value of $\alpha$ is determined by $U_{i}\left(s_{i}-0.5,20.5-s_{i}\right)=U_{i}(0,0)=0$, with $s_{i}$ being the decision number of the first decision under which the subject accepts the distribution of the sender.

$$
\alpha_{i}=\frac{s_{i}-0.5}{21-2 s_{i}}
$$

In the responder's role, selfish agents should always accept the distribution proposed as soon as the share they receive is strictly positive. The later the agent switches from rejecting to accepting the distribution, the higher his value of $\alpha$.

Risk aversion The predictions of the agents' behavior in the two-stage game hold for risk-neutral subjects. Risk aversion of subjects can however affect the decisions of agents concerning the choice of the payment scheme. This measure is used as a control. To elicit the risk aversion of the subjects, we used the lottery procedure of Holt and Laury (2002).

The subjects filled out a questionnaire with 10 decisions. Each decision consists of a choice between two paired lotteries, option $a$ and option $b$. The payoffs for the option $a$ are either $€ 2$ or $€ 1.60$, whereas the riskier option $b$ pays either $€ 3.85$ or $€ 0.10$. In the first decision, the probability of the high payoff for both options is $1 / 10$. In the second decision, the probability increases to $2 / 10$. Similarly, the chances of receiving the high payoff for each decision increase as the number of the decision increases. When the probability of the higher payoff is large enough, subjects should cross over from option $a$ to option $b$. Risk neutrality corresponds to a switch at the fifth decision, while risk loving subjects are expected to move earlier and risk averse subjects at the sixth decision and after. 


\subsection{Experimental procedures}

The experiments have been conducted at the GATE laboratory, Lyon, France. The experiment was computerized using the Regate software (Zeiliger, 2000). By using the ORSEE software (Greiner, 2004), we recruited 118 under-graduate students from three business or engineering schools, trying to guarantee a fair gender distribution in each session (52.54 per cent of male participants in total). Three sessions with 18 subjects, two with 22 subjects and one with 20 subjects were organized; three for the benchmark treatment and three for the choice treatment. The game was composed of 9 sequences of 5 periods. 45 observations are collected for every subject that conducts to a total of 5310 observations.

Every participant was summoned at two different days with one week of difference. When registering for the session of the first week, subjects committed themselves to participate in the second-week session. They were informed, in the invitation by E-mail, that they will receive their monetary gain only at the end of the second-week session. During the first week, the preferences were elicited. During the second week, the game was played. The subjects participating in a particular first session are not necessarily allocated to the same second session. They registered for the second session at the end of the first one. We separated the sessions eliciting preferences from the game sessions to avoid any potential influence from one part on the other one and to limit confusion of subjects.

Upon arrival, each subject received a participant identifyer in order to match the data between the two sessions anonymously. For every session, all participants were randomly assigned to a computer. Instructions were distributed and read aloud. Questions were answered in private. The participants had to answer a series of questions to verify their understanding of the instructions. The experiment started once all the participants answered correctly. No communication was allowed.

In the sessions of the first week, the subjects completed first the risk-aversion questionnaire. Subjects noted on a sheet of paper the option they chose for each of the 10 lottery decisions. After all participants had made their decisions, the sheets of papers were collected. Only one decision is used for the computation of subjects' payoffs. At the end of the sessions of the second week, at the moment of receiving his payment, each subject had to throw a ten-sided die twice: once to select the decision to be considered and a second time to determine her payoff for the option chosen. The other decisions asked in the first week were computerized. The subjects answered first the modified dictator game and then 
the ultimatum game.

In the sessions of the second week, in the Benchmark treatment, at the beginning of the session and for its whole duration, 10 subjects were allocated the revenue-sharing scheme and the others were compensated under the competitive scheme. ${ }^{14}$ In the Choice treatment, at the beginning of every sequence, each subject had to tick either the "mode $\mathrm{X}$ " box (revenue-sharing scheme) or the "mode Y" box (competitive scheme) to choose his payment scheme for the current sequence. In both treatments, they selected their effort level by choosing between the "choice A" (low effort level) and the "choice B" (high effort level). The computer program determined the situation (high or low) in which each agent was, depending on the probabilities computed. At the end of every period, each subject received a feedback on his potential payoff and on the potential payoff of his co-worker. In every new sequence, the subjects who chose the same payment scheme were randomly reshuffled in pairs.

All the transactions, except the lottery, were conducted in points, with conversion into Euros at a rate of 4 points $=€ 1$ for the preferences elicitation session and at a rate of 3 points $=€ 1$ for the game session. In the first week sessions, the Holt and Laury's lottery was paid and one of the two games was selected randomly for the payments. In the second week sessions, two periods in different sequences, identical for all subjects, were picked randomly to determine the payments. All periods were not paid because in this case, subjects would have received their average payoff, that kills inequality between agents. For the totality of the experiment, the payment consisted of the sum of payoffs during each session plus the lottery payment and a $€ 6$ show-up fee (€3 for each session). The totality of the payments and the actual roles of the subjects were announced only at the end of the second week for each participant. On average, the subjects earned $€ 19.59$.

\section{$3 \quad$ Experimental results}

After a brief presentation of the agents' preferences, we analyze the determinants of the agents' choices between the competitive and the revenue-sharing payment schemes. The consequences of the self-selection of agents on efficiency are then presented.

\footnotetext{
${ }^{14}$ As the number of participants under each session can be 18, 20 or 22, and an even number of subjects is required under each payment scheme, we forced 10 participants to be compensated under the revenuesharing scheme. Then, the number of participants compensated under the competitive scheme can be 8 , 10 or 12 .
} 


\subsection{Distribution of preferences}

The measures of preferences indicate that the subjects are heterogeneous in their inequity aversion degrees. $18.6 \%$ of the 118 subjects are purely selfish $(\alpha=\beta=0), 22 \%$ are averse to advantageous inequity but not averse to disadvantageous inequity ( $\alpha=0$ and $\beta \neq 0$ ), $20.3 \%$ are averse to disadvantageous inequity but not averse to advantageous inequity $(\beta=0$ and $\alpha \neq 0)$ and then $39.1 \%$ are averse to both advantageous and disadvantageous inequity aversion $(\beta \neq 0$ and $\alpha \neq 0) .{ }^{15}$ Figure 2 represents the distribution of the subjects in terms of their degrees of disadvantageous inequity aversion, $\alpha$, and advantageous inequity aversion, $\beta$.

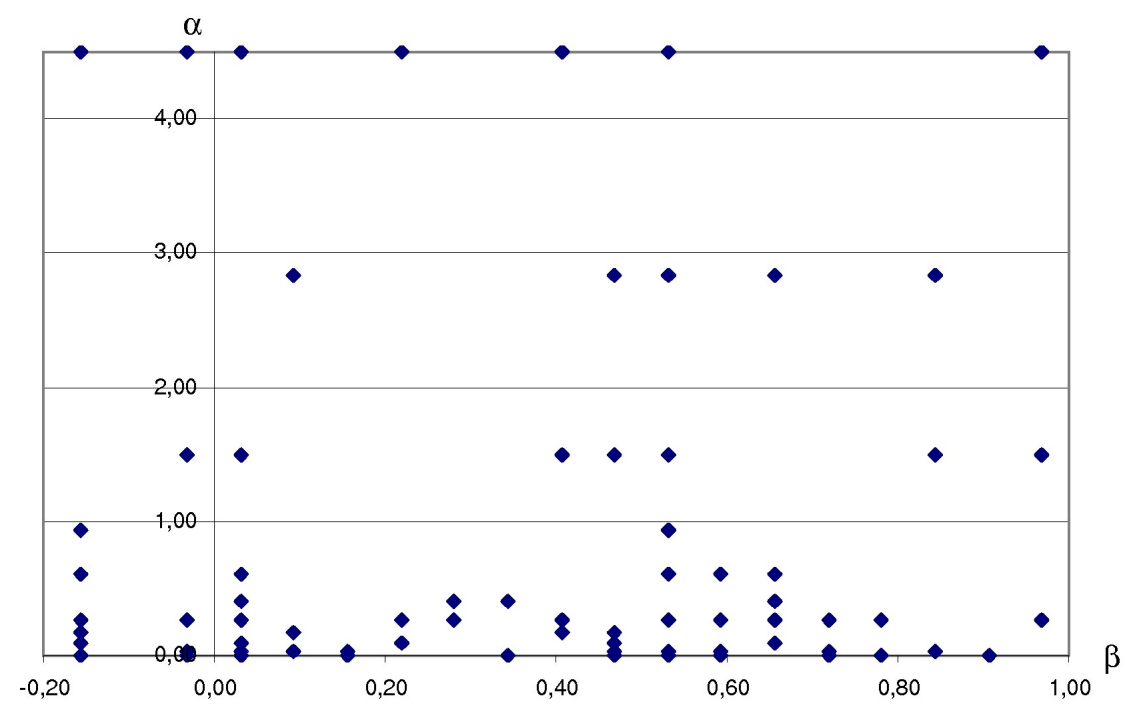

Figure 2: Distribution of the subjects in function of $\alpha$ and $\beta$

A Kolmogorov-Smirnov exact test does not reject the hypothesis of equality of distribution functions of inequity aversion degrees between the benchmark and the choice treatments $(\alpha, z=0.088, p=0.977$ and $\beta, z=0.183, p=0.278)$. We also observe that advantageous inequity aversion is not significantly correlated to disadvantageous inequity aversion of agents (Spearman's test, $z=0.027, p=0.776$ ). Moreover, the correlation between the agents' levels of inequity aversion and their level of risk aversion is not significant (Spearman's test for advantageous inequity aversion, $z=0.050, p=0.593$ and for disadvantageous inequity aversion, $z=0.047, p=0.616) .{ }^{16}$

\footnotetext{
${ }^{15} 13.5 \%$ of the subjects have $\beta<0$. These subjects feel envy preferences

${ }^{16}$ We observe higher proportions of risk averse and very risk averse subjects but a lower proportion of risk neutral subjects than in Holt and Laury's pool of subjects. A Kolmogorov-Smirnov exact test does not reject the hypothesis of equality of distribution functions between the benchmark and the choice treatments $(z=0.093, p=0.960)$.
} 
In order to stick to both the model and the data, we have chosen the threshold of 0.35 to differentiate subjects by their degree of disadvantageous inequity aversion, $\alpha$. It corresponds to $\alpha=\left.\alpha^{C}(\beta)\right|_{\rho_{C}=0}$ with $\beta=0$, i.e. $5.1 \alpha+3.7 \beta=1.8$ for $\beta=0$, that is theoretically defined as a threshold of decisions. The threshold of 0.15 is chosen to differentiate the agents by their degree of advantageous inequity aversion, $\beta$. Table 3 presents the proportion of subjects in each category.

\begin{tabular}{ccc}
\hline \hline Category of subjects & Benchmark T. & Choice T. \\
\hline$\alpha<0.35$ and $\beta<0.15$ & $20 \%$ & $38 \%$ \\
$\alpha<0.35$ and $\beta \geq 0.15$ & $45 \%$ & $26 \%$ \\
$\alpha \geq 0.35$ and $\beta<0.15$ & $13 \%$ & $12 \%$ \\
$\alpha \geq 0.35$ and $\beta \geq 0.15$ & $22 \%$ & $24 \%$ \\
\hline
\end{tabular}

Table 3: Distribution of inequity aversion categories

A Fisher exact test rejects the hypothesis of equality of distribution functions between the benchmark and the choice treatments for the categories $\alpha<0.35$ with $\beta<0.15$ and $\alpha<0.35$ with $\beta \geq 0.15$ (respectively, $p=0.016$ and $p=0.015$ ) but does not reject it for $\alpha \geq 0.35$ with $\beta<0.15$ and $\alpha \geq 0.35$ with $\beta \geq 0.15$ (respectively, $p=0.418$ and $p=0.375) \cdot{ }^{17}$

\section{$3.2 \quad$ Sorting}

The competition payment scheme is chosen on average in $38.5 \%$ of the decisions but a lower proportion of subjects choose the competition for their first decision (25.9\%). It is clearly observed that subjects are heterogeneous in their choice behaviors. Three categories of subjects can in fact be differentiated for the whole duration of the experiment. We distinguish subjects who choose the competition in less than three sequences, "competition -" (45\% of subjects), subjects who choose the competition in at least six sequences, "competition $+"(24 \%$ of subjects $)$, and an intermediate category, "competition =" (31\% of subjects).

\footnotetext{
${ }^{17}$ We observe higher proportions of inequity averse agents with low inequity considerations compared to the results in Fehr and Schmidt (1999) and of Blanco, Engelmann and Normann (2006). The subjects from our pool may be less affected by the situation of other subjects because of their education path. Indeed, the subjects are mainly from "grandes écoles" (business and engineering schools). Nevertheless, we may suppose that the only impact of this specificity of our pool would be a reduction of the effect of social preferences in our results. We also note that, as Blanco, Engelmann and Normann (2006), the hypothesis of the Fehr and Schmidt's model, $\alpha \geq \beta$, is not always verified: $41 \%$ of subjects present $\beta>\alpha$ in our experiment and $38 \%$ in the experiment of Blanco, Engelmann and Normann (2006).
} 
A multivariate analysis allows to understand the determinants of the choice of the competition, ceteris paribus. It leads to the result 1.

Result 1. Disadvantageous inequity aversion negatively affects the choice of the competition.

We use probit regressions with random effects to identify the determinants of the choice of the competition. As decisions of subjects are repeated, we adjust standard errors for intragroup correlation, that is to say that we cluster regressions on individuals. Several estimations are conducted depending on the sequences of the game: we separate the estimations for the first sequence, for sequences 2 to 5 and for sequences 6 to 9 .

Estimations are based on dummies controlling for sessions and individual characteristics such as age, gender and the fact of having already participated in an experiment. ${ }^{18}$ We also include an explicative variable related to the history of the game. It represents the current success rate of subjects under the competition. It is the ratio between the current number of high situations and the current number of periods compensated under the competitive scheme. The other explicative variables consist of risk aversion, measured by the number of safe choices in the Holt and Laury's lottery (2002) (coded from 1 to 10) and inequity aversion degrees. A dummy takes the value 1 when agents have a degree of disadvantageous inequity aversion higher or equal to 0.35 and a second dummy takes the value 1 when agents have a degree of advantageous inequity aversion higher of equal to 0.15. As the model predicts that agents with both low advantageous and low disadvantageous inequity aversion prefer the competition, we control for this effect by introducing a dummy taking the value 1 when $\beta<0.15$ and $\alpha<0.35$.

Table 4 displays the marginal coefficients of the probit regressions with random effects and clustering on individuals explaining the choice of the competitive payment scheme.

In the first half of the experiment (sequences 2 to 5), individual preferences of agents drive directly their choice of payment scheme. Subjects with high disadvantageous inequity aversion are significantly less likely to choose the competition. The probability of choosing the competition is $20 \%$ lower for subjects with a disadvantageous inequity aversion degree higher than 0.35 compared with others. In the second half of the experiment (sequences 6 to 9 ), only the variable indicating the success rate under the competition is significant.

\footnotetext{
${ }^{18}$ Except the variable indicating the gender of agents, we do not show in the regressions the other variables. They are just control variables.
} 


\begin{tabular}{|c|c|c|c|c|}
\hline \multicolumn{5}{|c|}{ Dependent variable: Choice of the competition } \\
\hline & Sequence 1 & Sequences 2-5 & Sequences 6-9 & Sequences 2-9 \\
\hline \multirow[t]{2}{*}{ sequence } & & $-0.082^{* \star \star}$ & 0.007 & $-0.031^{* \star *}$ \\
\hline & & $(0.031)$ & $(0.022)$ & $(0.009)$ \\
\hline \multirow[t]{2}{*}{ gender $(1=$ male $)$} & -0.024 & -0.033 & 0.047 & 0.017 \\
\hline & $(0.115)$ & $(0.078)$ & $(0.105)$ & $(0.080)$ \\
\hline \multirow[t]{2}{*}{ risk aversion } & $-0.184^{\star \star \star}$ & $-0.102^{\star \star \star}$ & -0.051 & $-0.076^{\star \star}$ \\
\hline & $(0.048)$ & $(0.033)$ & $(0.045)$ & $(0.033)$ \\
\hline \multirow[t]{2}{*}{ alpha $\geq 0.35$} & 0.035 & $-0.200^{\star \star}$ & 0.058 & -0.071 \\
\hline & $(0.153)$ & $(0.092)$ & $(0.150)$ & $(0.104)$ \\
\hline \multirow[t]{2}{*}{ beta $\geq 0.15$} & 0.051 & 0.175 & 0.101 & 0.166 \\
\hline & $(0.173)$ & $(0.134)$ & $(0.208)$ & $(0.131)$ \\
\hline \multirow[t]{2}{*}{ alpha $<0.35 *$ beta $<0.15$} & 0.053 & 0.042 & 0.033 & 0.066 \\
\hline & $(0.228)$ & $(0.170)$ & $(0.244)$ & $(0.167)$ \\
\hline success rate under the & & $0.439^{* * *}$ & $1.008^{* * *}$ & $0.553^{\star * *}$ \\
\hline competition & & $(0.160)$ & $(0.257)$ & $(0.166)$ \\
\hline Observations & 58 & 232 & 232 & 464 \\
\hline Wald $\chi^{2 / L R} \chi^{2}$ & 26.160 & 45.310 & 30.730 & 44.150 \\
\hline Prob $>\chi^{2}$ & 0.002 & 0.000 & 0.001 & 0.000 \\
\hline Log likelihood & -24.221 & -135.339 & -127.758 & -274.238 \\
\hline Pseudo $\mathrm{R}^{2}$ & 0.269 & 0.142 & 0.173 & 0.122 \\
\hline
\end{tabular}

${ }^{*}$ significant at $10 \% ;{ }^{* *}$ significant at $5 \%$; *** significant at $1 \%$

Table 4: Determinants of the choice of the competition

Nevertheless, it does not mean that inequity preferences of agents do not play any role when agents get some experience in the game. Indeed, the choice of the competition based on inequity preferences is endogenized by past results. Disadvantageous inequity aversion of subjects consequently plays an indirect role on the choice of the competition in the second half of the experiment through past results. Moreover, the marginal effect of the success rate under the competition is more than two times higher in the second half compared to the first half ( $1 \%$ versus $0.44 \%$ ). Along with inequity aversion in the first half of the experiment, the higher risk aversion of the subjects, the lower their probability of choosing the competition. We also observe that risk aversion of subjects is the only determinant of the choice of the competition in their first choice (sequence 1).

These results suggest that, in an unknown environment, only the risk preferences of subjects influence their choice. Risk averse agents prefer to choose a payment scheme that guarantees a low variance between the agents' payments. In sequences just following the first sequence, disadvantageous inequity aversion is the main individual characteristic that influences the agents' choice. Social preferences of agents influence their decision of choice once they have had the chance to test the game. From the analysis of sequences 6 to 
9, we can infer, when the agents are sufficiently experienced, that their preferences drive indirectly their choice of payment scheme through the results already observed in previous periods.

The theory predicts that inequity averse agents with a sufficiently high advantageous or disadvantageous inequity aversion prefer to avoid the competition. Nevertheless, the advantageous inequity aversion of agents does not drive the choice of the payment scheme. An explanation can come from the fact that all agents have the possibility of choosing their payment scheme in the choice treatment. Advantageous inequity averse agents may not consider winning as an advantageous unequal situation because all agents entered voluntarily in this payment scheme. Therefore, they may not feel bad because they earn more than the other agent considering that choosing the competition supposes accepting the risk of losing. ${ }^{19}$

\subsection{Efficiency}

The previous results stress the existence of a sorting effect of payment schemes. We study in this section the consequences of such a sorting on efficiency measured by the average effort level and the average payoffs of agents under both the competition and the revenue-sharing scheme.

\subsubsection{Average effort level}

The consequence in terms of average effort level of the sorting effect of payment schemes leads to the result 2 .

Result 2. The average effort level is increased under the competition when self-selection of agents is allowed but no significant change occurs under the revenue-sharing scheme.

The effort level variable is binary. We coded the high effort level, $e_{H}$, by 1 and the low effort level, $e_{L}$, by 0 . Table 5 displays summary statistics about the mean of effort by payment scheme and by treatment.

\footnotetext{
${ }^{19}$ The symmetric reasonning for disadvantageous inequity aversion is not true. In fact, an agent who dislikes earning less than the other agent does not feel better if the other agent has freely chosen his payment scheme.
} 


\begin{tabular}{lccccc}
\hline \hline & Sequence 1 & Sequences 2-5 & Sequences 6-9 & Sequences 2-9 & All sequences \\
\hline Competition & & & & & \\
Benchmark tr. & 0.66 & 0.71 & 0.70 & 0.70 & 0.70 \\
Choice tr. & 0.80 & 0.76 & 0.78 & 0.77 & 0.77 \\
\hline Revenue-sharing & & & & & \\
Benchmark tr. & 0.67 & 0.64 & 0.71 & 0.67 & 0.67 \\
Choice tr. & 0.64 & 0.58 & 0.71 & 0.65 & 0.65 \\
\hline
\end{tabular}

Table 5: Summary statistics on average effort level

The average effort level under the revenue-sharing payment scheme equals 0.65 in the choice treatment. It is not different from the average effort level exerted in the benchmark treatment (Mann-Whitney $\mathrm{U}$ test, $z=1.523, p=0.128$ ). The average effort level under the competition equals 0.77 in the choice treatment and it is significantly higher than the average effort level exerted in the benchmark treatment (Mann-Whitney U test, $z=3.935$, $p<0.001)$. This result is in accordance with the theory. The agents who choose the competition are motivated by this payment scheme and exert the high effort level. Under the revenue-sharing scheme, the average effort level is not decreased. It is nevertheless not increased either. ${ }^{20}$

A refinement of this result going in the sense of the self-selection hypothesis gives the result 3 .

Result 3. An agent who chooses a payment scheme more frequently than other agents exerts, on average, a higher effort level than others under this payment scheme.

The figure 3 displays the average effort levels under both payment schemes depending on the number of times the agents chose the competitive payment scheme.

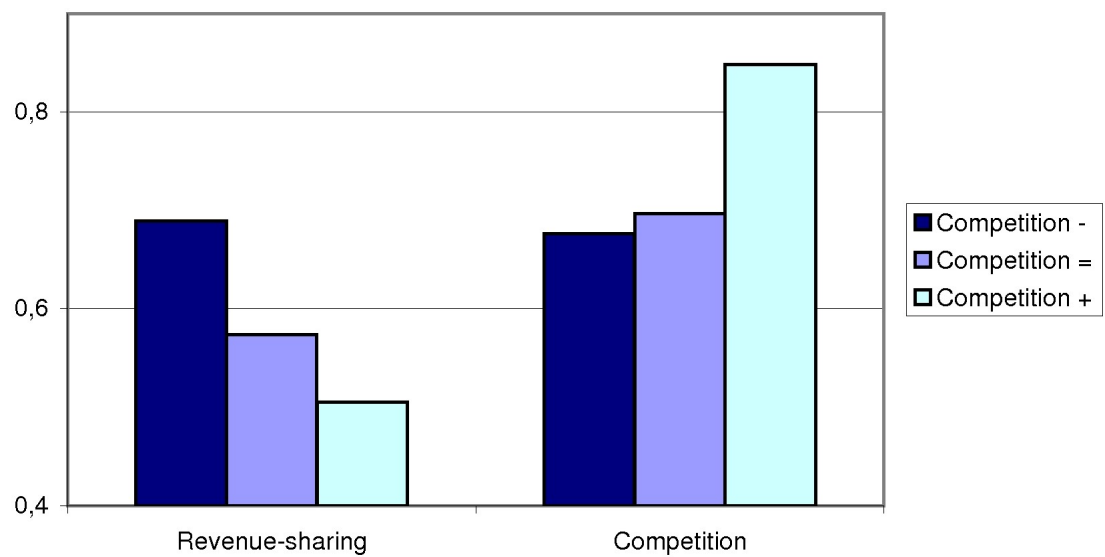

Figure 3: Average effort level by category of subjects

\footnotetext{
${ }^{20}$ The validity of the reasons advanced theoretically will be discussed latter on, after the study of the determinants of the effort decisions.
} 
This graph shows that the agents who choose the competition less than three times exert a significantly higher effort level than others under the revenue-sharing scheme (Wilcoxon rank-test: $z=15.159, p<0.001$ and $z=23.744, p<0.001)$ and the agents who choose the competition six times or more exert a significantly higher effort level than others under the competition (Wilcoxon rank-test: $z=6.461, p<0.001$ and $z=14.891, p<0.001$ ). We also notice that the agents who choose more often the competition exert an average effort level clearly higher under the competition than under the revenue-sharing scheme (Wilcoxon rank-test, $z=17.666, p<0.001)$. Agents who choose more often the revenue-sharing scheme exert the same effort level under this payment scheme and under the competitive scheme (Wilcoxon rank-test, $z=0.362, p=0.717$ ). The self-selection of agents is then efficient, especially under the competitive payment scheme. This result suggests a sorting effect of payment schemes. ${ }^{21}$ How does this sorting effect relate to the social preferences of the agents?

To understand the effect of individual preferences on the effort decisions, we compare the results of the regressions in the choice treatment with those of the benchmark treatment. Tables 6 and 7 show the econometric estimations of effort decisions under both payment schemes. A probit model with random effects and clustering on individuals is used. The individual preferences as explanatory variables consist of risk aversion and disadvantageous and advantageous inequity aversion. The history of the game and interactions between agents are characterized by the effort level at the previous period of the subject's coworker, the absolute value of the difference between payoffs of both subjects in the group at the previous period and also the current proportion of high situations of the subject.

These estimations lead to the results 4 and 5 .

\footnotetext{
${ }^{21}$ It cannnot be explained by a learning effect. The evolution of effort levels depending on the number of choices does not show evidence of it.
} 


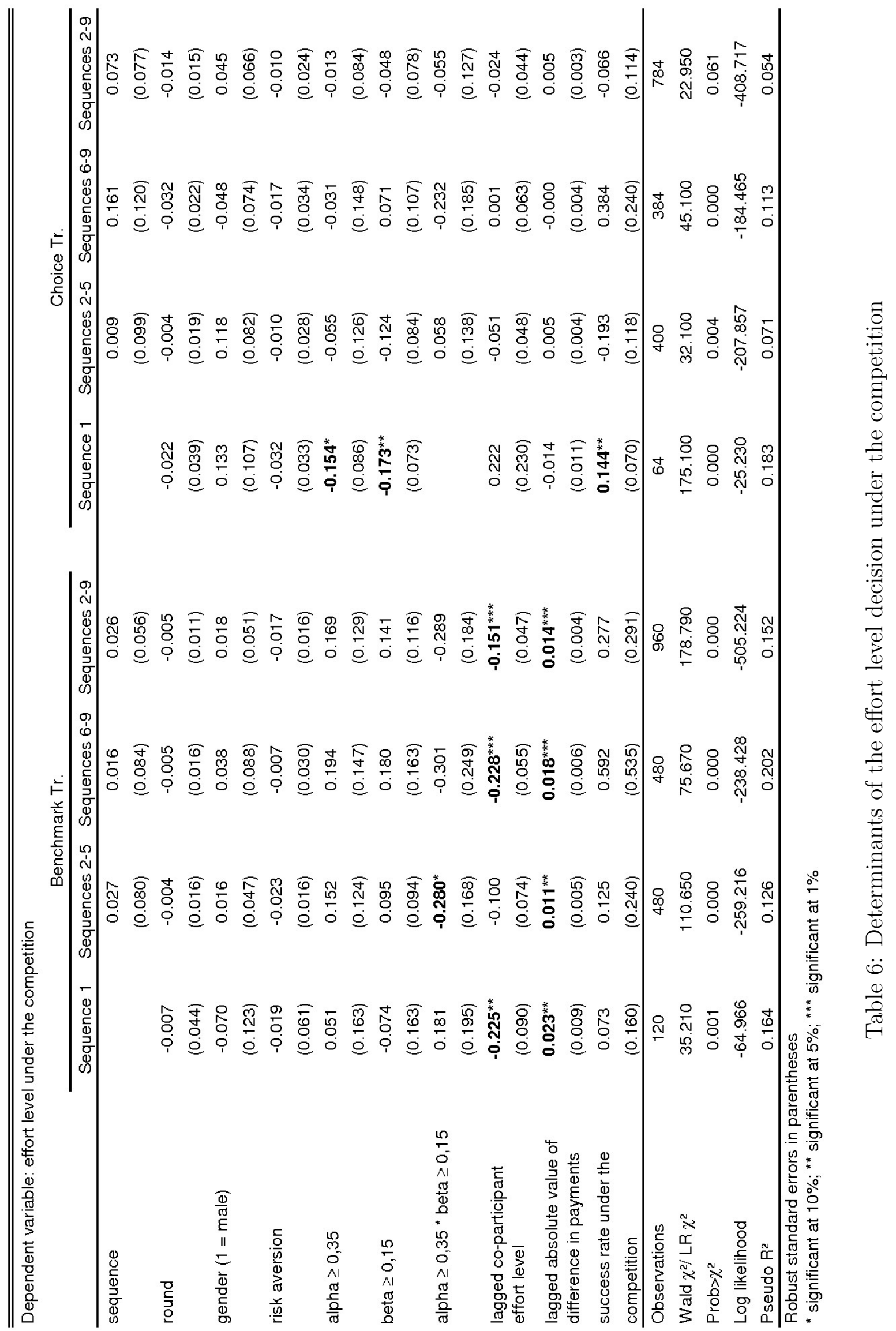




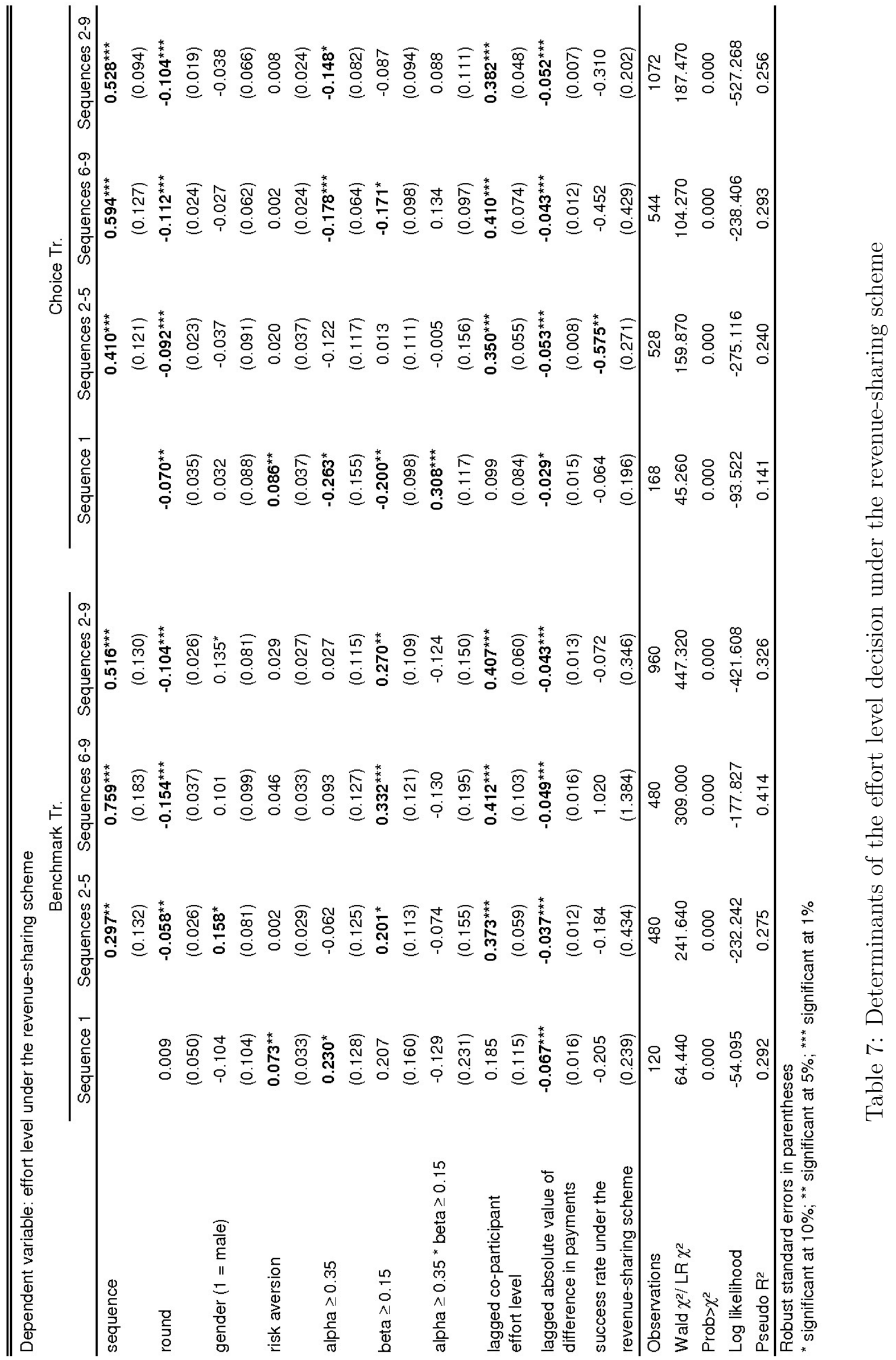


Result 4. The effort level decisions in the competition are not driven by inequity preferences when self-selection is allowed.

When the subjects are allowed to choose their payment scheme, their individual preferences have no effect on their effort in the competition as predicted by the theory (except at the first sequence ${ }^{22}$ ). Preferences serve to steer their choice of payment scheme. Moreover, the past effort of the co-participant, the past difference between payoffs and the success rate in the competition, are also not significant. This is in accordance with the model setting that selfish agents, or agents with low inequity aversion, prefer the competition to the revenue-sharing scheme. Whatever the other agent's behavior and whatever the past results, the utility of these agents is always maximized when the high effort level is played.

In the absence of choice, the inequity aversion of the subjects influences the effort decision. Subjects with both high advantageous and disadvantageous inequity aversion degrees exert a lower effort level than others in the first half of the experiment. In the second half, this variable becomes insignificant. Nevertheless, the effort level of the coworker has a negative impact on the effort level decision. As the inequality between payoffs is increased with the effort level, we may deduce that, after some interactions, agents' inequity aversion plays a role only when the inequality is sufficiently high, that means when the other subject plays the high effort level.

Therefore, efficiency of the competition is increased when the subjects are allowed to choose their payment scheme because this mode attracts the selfish agents and the latter are motivated by the competition. The self-selection of subjects in the competition is efficient.

Result 5. In the first half of the experiment, when self-selection is allowed, the effort level decisions in the revenue-sharing scheme are not driven by inequity preferences of agents. Their effect is significant again in the second half due to a heterogeneity of previous effort decisions.

This result corroborates with the result of the analysis of sorting. Inequity aversion influences the payment scheme choice in the first half of the experiment then, they do not drive effort decisions once under a particular payment scheme. In the second half of the experiment, agents base their choice of payment scheme only indirectly on inequity

\footnotetext{
${ }^{22}$ The negative and significant effect of inequity aversion indicators at the first sequence may be explained by the fact that subjects who chose the competition at the first sequence chose it only for a test.
} 
preferences through the history of the game then, inequity aversion drives agents' effort level decisions.

In the absence of choice, subjects with high advantageous inequity aversion exert a significantly higher effort level than others under the revenue-sharing payment scheme for the whole experiment. This result is in accordance with the theory. However, when the agents choose their payment scheme, agents with high advantageous or high disadvantageous inequity aversion are less likely than others to exert the high effort level in the second half of the experiment. Why does inequity aversion play a role again on the decisions of effort after some interactions when the agents self-select?

The heterogeneity of effort behaviors in the first half of the experiment could be a potential reason. The theory predicts this heterogeneity because of a potential coordination problem due to the multiplicity of equilibria and/or to the potential existence of subjects who choose the revenue-sharing scheme without being motivated by it exerting the low effort level. Heterogeneity of effort behaviors is in fact supported by the data. In the first period of sequences 2 to 5 under the revenue-sharing scheme, $52 \%$ of subjects see their co-worker exerting a different effort level. ${ }^{23}$ Therefore, if an agent very concerned by disadvantageous inequality has been cheated, his future behavior is strongly affected by it and his probability to exert the high effort level is decreased. Moreover, agents with high advantageous inequity aversion exert also a lower effort level than others. One potential explanation is that these agents have been more often cheated. Indeed, they receive significantly lower payoffs during sequences 1 to 5 compared to other agents (the average payoffs for sequences 1 to 5 equals 10.6 for subjects with $\beta \geq 0.15$ whereas it equals 12.1 for subjects with $\beta<0.15$. Wilcoxon rank test, $z=3.060, p=0.002$ ).

In the two treatments, effort behaviors depend on others' behaviors. We observe that the subjects are more likely to exert the high effort level when the other agent has chosen the high effort level at the previous period. Moreover, subjects are sensitive to the difference between payoffs at the previous period that decreases their probability to choose the high effort level.

The main consequence of the opportunity given to the agents to choose freely their payment scheme is that the self-selection of the agents is efficient under the competition but

\footnotetext{
${ }^{23}$ This frequence is decreasing as the relationship progresses because subjects learn the type and the behavior of their co-worker and adapt in this sense their effort decision.
} 
imperfect under the revenue-sharing scheme. Subjects who choose often the competition feel in accordance with this type of incentives and are largely more motivated by it than by the revenue-sharing scheme. However, subjects compensated under the revenue-sharing scheme have heterogeneous behaviors and then the average effort level is not increased with self-selection.

\subsubsection{Average payoffs of agents}

Do agents benefit also from the opportunity of choosing their payment scheme? Is it costly for the agents to follow their preferences or is it a good manner to maximize their payoffs? Table 8 represents the average payoffs of agents in the benchmark and the choice treatments under both payment schemes depending on the number of times they choose the competition.

\begin{tabular}{ccccc}
\hline \hline & Benchmark Tr. & \multicolumn{3}{c}{ Choice Tr. } \\
\cline { 2 - 5 } Category of subjects & Average & Average & Competition & $\begin{array}{c}\text { Revenue- } \\
\text { sharing }\end{array}$ \\
\hline Competition - & 11.5 & 11.8 & 11.7 & 11.8 \\
Competition $=$ & - & 11.0 & 11.1 & 10.9 \\
Competition + & 11.5 & 12.1 & 12.5 & 10.2 \\
\hline
\end{tabular}

Table 8: Average payoffs by category of subjects

Result 6. Subjects maximize their payoffs by following their preferences.

The average payoff of subjects under both payment schemes in the benchmark treatment equals 11.5 points. The subjects who prefer one of the two payment schemes in the choice treatment receive a higher average payoff under the preferred payment scheme than in the benchmark treatment. They receive also a higher average payoff than the other categories of agents under this payment scheme.

Agents who prefer one payment scheme benefit from the possibility to choose their payment scheme (agents in the choice treatment of the types Competition + and Competition -) receive a higher average payoff than agents in the benchmark treatment (t-test, respectively, $p=0.062$ and $p=0.109)$ whereas agents who hesitate between the two payment schemes receive a lower payoff ( $\mathrm{t}$-test, $p=0.023$ ). Moreover, in the choice treatment, the agents who choose the competition six times or more receive an average payoff significantly higher under the payment scheme they choose the most frequently ( $\mathrm{t}$-test, $p=0.004$ ). It is 
also higher than the average payoff of other agents (t-test, $p=0.023$ ). Agents who choose the revenue-sharing scheme more than six times do not receive a significantly higher average payoff in the revenue-sharing scheme compared to the competition (t-test, $p=0.220$ ). Their average payoff is nevertheless significantly higher than others' in the revenue-sharing scheme (t-test, $p<0.001$ ).

These results are in the continuation with the previous results. Agents who often choose one payment scheme are more motivated by it than hesitant agents. They are then more able to reach the Pareto optimum and then to make higher payoffs.

\section{Conclusion}

Our experiment gives some evidence on the sorting effect of payment schemes and its consequences, depending on agents' inequity aversion. It is observed that agents with high disadvantageous inequity aversion prefer to be compensated by a revenue-sharing scheme. More precisely, in the first half of the experiment, this effect is direct but, in the second half, disadvantageous inequity aversion of subjects plays an indirect role through the effect of past results. It is also observed that risk aversion decreases the probability of choosing the competition. The effect of risk aversion is higher for the first choice of payment scheme.

The self-selection of agents is efficient under the competition but imperfect under the revenue-sharing scheme. Indeed, the efficiency of the competition is significantly increased when agents are allowed to choose their payment scheme. The agents who self-select the competition are motivated by this payment scheme and exert a higher average effort level compared to the average effort level of agents who are imposed to be compensated by the competition. Thus, inequity preferences have no effect on the effort decision when self-selection is allowed. The average effort level is nevertheless not improved under the revenue-sharing scheme when agents are allowed to choose freely their payment scheme. The reason may be related to the heterogeneity between agents' effort behaviors in the first half of the experiment. These results are in accordance with the theoretical predictions. From the agents' point of view, it appears that the agents who have a preference for a specific payment scheme benefit from the possibility to choose their payment scheme. Therefore, subjects maximize their payoffs by following their preferences to choose their payment scheme. 
In business settings, a personnel manager is interested in searching for an incentive mechanism that will lead to an increase of the average productivity of the employees and then of the company. Our experimental results suggest that two types of labor market must be differentiated. On a market with high costs of mobility for agents, the personnel manager should evaluate employees' social preferences to calibrate which performancebased payment scheme is the most appropriate to provide incentives to workers. Depending on agents' social preferences, the efficiency of a variable payment scheme may not be such as expected. On a flexible market, the situation is different. In fact, agents may self-select between firms using different payment schemes, provided that diverse organizations exist on the market. In this case, an evaluation of agents' inequity aversion may be useless because their choice of payment scheme indicates their individual preferences. The institution of various performance-based payments schemes may be valuable for its efficiency.

The results obtained underline the importance of taking into account the effect of selfselection between various payments schemes. It adds to the already existing literature on self-selection between different payment schemes showing that agents' behaviors may be different when the choice of a particular payment scheme is allowed. The research on the influence of inequity aversion degrees on agents' self-selection should be completed by heterogeneity in ability levels. This study can also be extended to other payment schemes. Moreover, differentiating the source of social norms between a self-selection of agents and an evolution of the effect of preferences and of their hierarchy should be analyzed more precisely in the future.

\section{References}

[1] Akerlof, Georges A. and Yellen, Janet L. (1990). "The Fair Wage-Effort Hypothesis and Unemployment." Quarterly Journal of Economics, 105, pp. 255-83.

[2] Bandiera, Oriana, Barankay, Iwan and Rasul, Imran (2007). "Incentives for Managers and Inequality Among Workers: Evidence From a Firm Level Experiment." Quarterly Journal of Economics, 122(2), 729-73.

[3] Bellemare, Charles and Shearer, Bruce S. (2006). "Sorting, Incentives and Risk Preferences: Evidence from a Field Experiment." IZA Discussion Paper $N^{\circ}$ 222\%.

[4] Blanco, Mariana, Engelmann, Dirk and Normann, Hans-Theo (2007). "A WithinSubject Analysis of Other-Regarding Preferences." Working Paper, Royal Halloway College, University of London. 
[5] Burlando, Roberto M. and Guala, Francesco, (2005). "Heterogeneous agents in public goods experiments." Experimental Economics, 8(1), pp. 35-55.

[6] Bonin, Holger, Dohmen, Thomas, Falk, Armin, Huffman, David and Sunde, Uwe (2007). "Cross-Sectional Earnings Risk and Occupational Sorting: The Role of Risk Attitudes." Labour Economics, forthcoming.

[7] Cabrales, Antonio and Calvò-Armengol, Antoni (2008). "Interdependent Preferences and Segregating Equilibria." Journal of Economic Theory, 139, pp. 99-113.

[8] Cabrales, Antonio, Miniaci, Raffaele, Piovesan, Marco and Ponti, Giovanni (2007). "An Experiment on Markets and Contracts: Do Social Preferences Determine Corporate Culture?" University of Copenhagen Working Paper $N^{\circ}$ 08-06.

[9] Cadsby, Bram C., Song, Fei and Tapon, Françis (2007). "Sorting and Incentive Effects of Pay for Performance: An Experimental Investigation." Academy of Management Journal, 50(2), pp. 387-405.

[10] Carpenter, Jeffrey and Seki, Erika (2005). "Do Social Preferences Increase Productivity? Field Experimental Evidence from Fishermen in Toyama Bay." IZA Discussion Paper $N^{\circ} 169 \%$.

[11] Chiappori, Pierre-André and Salanié, Bernard (2003). "Testing Contract Theory: A Survey of Some Recent Work." In: M. Dewatripont, L.P. Hansen, S. Turnovski, Advances in Economic Theory, Eight World Congress of the Econometric Society, Vol.1, Cambridge: Cambridge University Press, pp. 115-49.

[12] Clark, Andrew E. and Oswald, Andrew J. (1996). "Satisfaction and Comparison Income." Journal of Public Economics, 61(3), pp. 359-81.

[13] Dannenberg, Astrid, Riechmann, Thomas, Sturm, Bodo and Vogt, Carsten (2007). "Inequity Aversion and Individual Behavior in Public Good Games: An Experimental Investigation." $Z E W$ Working Paper $N^{\circ}$ 0\%-034.

[14] Datta Gupta, Nalbanita, Poulsen, Anders and Villeval, Marie-Claire (2005). "Do (Wo)men Prefer (Non)Competitive Jobs?" Working Paper.

[15] Dohmen, Thomas and Falk, Armin (2006). "Performance Pay and Multi-Dimensional Sorting: Productivity, Preferences and Gender." IZA Discussion Papers N ${ }^{\circ} 2001$.

[16] Eriksson, Tor, Teyssier, Sabrina and Villeval, Marie-Claire (2008). "Self-Selection and the Efficiency of Tournaments." Economic Inquiry, forthcoming.

[17] Fehr, Ernst, Klein, Alexander and Schmidt, Klaus M. (2007). "Fairness and Contract Design." Econometrica, $75(1)$, pp.121-54.

[18] Fehr, Ernst and Schmidt, Klaus M. (1999). "A Theory of Fairness, Competition, and Cooperation." The Quarterly Journal of Economics, 114(3), pp. 817-868.

[19] Fischbacher, Urs and Gächter, Simon, (2006). "Heterogeneous social preferences and the dynamics of free riding in public goods." IEW Working Paper No. 261, University of Zurich. 
[20] Gächter, Simon and Thöni, Christian, (2005). "Social learning and voluntary cooperation among like-minded people." Journal of the European Economic Association, 3(2-3), pp. 303-314.

[21] Goddeeris, John H. (1988). "Compensating Differentials and Self-Selection: An Application to Lawyers." Journal of Political Economy, 96(2), pp. 411-28.

[22] Greiner, Ben (2004). "An Online Recruitment System for Economic Experiments." In Kurt Kremer, Volker Macho (eds.). Forschung und wissenschaftliches Rechnen, GWDG Bericht 63, Gttingen : Ges. fr Wiss. Datenverarbeitung, 2003, pp. 79-93.

[23] Grund, Christian and Sliwka, Dirk (2006). "Performance Pay and Risk Aversion." IZA Discussion Paper $n^{\circ} 2012$.

[24] Hamilton, Barton H.; Nickerson, Jack A. and Owan, Hideo, (2003). "Team Incentives and Worker Heterogeneity: An Empirical Analysis of the Impact of teams on Productivity and Participation." Journal of Political Economy, 111, pp. 465-497.

[25] Holmstrom, Bengt, (1982). "Moral Hazard in Teams." The Bell Journal of Economics, 13(2), pp. 324-340.

[26] Kahneman, Daniel, Knetsch, Jack L. and Thaler, Richard H. (1991). "Anomalies: The Endowment Effect, Loss Aversion, and Status Quo Bias." Journal of Economic Perspectives, 5(1), pp. 193-206

[27] Kahneman, Daniel and Tversky, Amos (1984). "Choices, Values and Frames." Journal of Political Economy, 98, pp. 1325-48.

[28] Keser, Claudia and Montmarquette, Claude (2007). "Voluntary Teaming and Effort." Working Paper $n^{\circ}$ \%45, German Institute for Economic Research.

[29] Kosfeld, Michael and von Siemens, Ferdinand (2007). "Competition, Cooperation, and Corporate Culture." IZA Discussion Paper $N^{\circ} 2927$.

[30] Lazear, Edward P. (2000). "Performance Pay and Productivity." American Economic Review, 90(5), pp. 1346-61.

[31] Lazear, Edward P., Malmendier, Ulrike and Weber, Roberto (2006). "Sorting in Experiments with Application to Social Preferences." NBER Working Paper $N^{\circ} 12041$.

[32] Lazear, Edward P. and Rosen, Sherwin (1981). "Rank-Order Tournaments as Optimum Labor Contracts." Journal of Political Economy, 89(5), pp; 841-64.

[33] Moldovanu, Benny and Sela, Aner (2001). "The Optimal Allocation of Prizes in Contests." American Economic Review, 91, pp. 58.

[34] Niederle, Muriel and Vesterlund, Lise (2007). "Do Women Shy away from Competition? Do Men Compete too Much?" Quarterly Journal of Economics, forthcoming.

[35] O'Dell, Carla and McAdams, Jerry L., (1987). "The Revolution in Employee Rewards." Compensation and Benefits Review, 19, pp. 68-73. 
[36] Pfeffer, Jeffrey (20077). "Human Resources from an Organizational Behavior Perspective: Some Paradoxes Explained" Journal of Economic Prespectives, 21(4), pp. $115-34$.

[37] Prendergast, Canice (1999). "The Provision of Incentives in Firms." Journal of Economic Literature, 37(1), pp. 7-63.

[38] Selten, Reinhard (1967). "Die Strategiemethode zur Erforschung des eingeschränkt rationalen Verhaltens im Rahmen eines Oligopolexperiments." Beiträge zur experimentellen Wirtschaftsforschung, Heinz Sauermann (ed.), Vol 1, Tübingen: J.C.B. Mohr (Siebeck), pp. 136-68.

[39] Teyssier, Sabrina (2007). "Optimal Group Incentives with Social Preferences and SelfSelection." GATE Working Paper $N^{\circ}$ 0\%-10.

[40] Torgler, Benno, Schaffner, Markus, Frey, Bruno S. and Schmidt, Sascha L. (2008). "Looking Awkward When Winning and Foolish When Losing: Inequity Aversion and Performance in the Field." CREMA Working Paper $N^{\circ}$ 2008-11.

[41] Tullock, Gordon, (1980). "Efficient Rent Seeking." In James M. Buchanan, Robert D. Tollison, and Gordon Tullock, (eds.). Toward a Theory of the Rent Seeking Society, College Station: Texas A\&M University Press, 1980, pp. 269-282.

[42] Zeiliger, Romain. A Presentation of Regate, Internet Based Software for Experimental Economics. http://www.gate.cnrs.fr/ zeiliger/regate/RegateIntro.ppt, GATE, 2000.

\section{Appendix}

Stage 2 - Equilibrium effort levels under the competition when payment schemes are imposed

For the derivation of the equilibrium, we consider the last period of the relationship and we solve by backward induction.

Under complete information on the type of agents, the utilities of agents are represented in the following matrix. The first term is the utility of an inequity averse agent and the second term is the utility of a selfish agent.

\begin{tabular}{cc|c|c|}
\multicolumn{2}{c}{ agent $j$} & $\mathrm{e}_{\mathrm{L}}$ \\
\cline { 3 - 4 } agent $i$ & $\mathrm{e}_{\llcorner}$ & $(8.5-4.5 \beta-4.5 \alpha ; 8.5)$ & $(11.2-6.3 \beta-4.9 \alpha ; 9.8)$ \\
\cline { 3 - 4 } & $\mathrm{e}_{H}$ & $(9.8-4.9 \beta-6.3 \alpha ; 11.2)$ & $(13-10 \beta-10 \alpha ; 13)$ \\
\cline { 3 - 4 } & &
\end{tabular}


A selfish agent has a dominant strategy that is to play the $e_{H}$ effort level. We must analyse inequity averse agents' behavior under incomplete information because they do not have any dominant strategy under the competition.

We suppose that the inequity averse agent only knows the existence of a proportion $(1-\rho)$ of selfish agents and a proportion $\rho$ of inequity averse agents as him. We assume that all inequity averse agents play the same effort level and that all selfish agents play their dominant strategy, $e_{H}$. The expected utilities of an inequity averse agent is written in the following matrix depending on his effort decision.

\begin{tabular}{cc|c|} 
agent $i$ & $\mathrm{e}_{\mathrm{L}}$ & agent $j$ \\
\cline { 3 - 3 } (inequity averse) & $\mathrm{e}_{\mathrm{H}}$ & $11.2-2.7 \rho_{\mathrm{C}}-\beta\left(6.3-1.8 \rho_{\mathrm{C}}\right)-\alpha\left(4.9-0.4 \rho_{\mathrm{C}}\right)$ \\
\cline { 3 - 3 } & &
\end{tabular}

An inequity averse agent decides to play $e_{H}$ if $\alpha\left(5.1+0.4 \rho_{C}\right)+\beta\left(3.7+1.8 \rho_{C}\right) \leq 1.8+$ $2.7 \rho_{C} \Longleftrightarrow \alpha \leq \frac{\left(1.8+2.7 \rho_{C}\right)-\beta\left(3.7+1.8 \rho_{C}\right)}{5.1+0.4 \rho_{C}}$. For the following, we call this inequality $\alpha \leq \alpha^{C}(\beta)$. For each type of agents, the equilibrium effort level is the same for both types of agents in a one-shot and in a repeated relationships.

\section{Stage 2 - Equilibrium effort levels under the revenue-sharing scheme when payment schemes are imposed}

For the derivation of the equilibrium, we consider the last period of the relationship and we solve by backward induction.

Under complete information on the type of agents, the utilities of agents are represented in the following matrix. The first term is the utility of an inequity averse agent and the second term is the utility of a selfish agent.

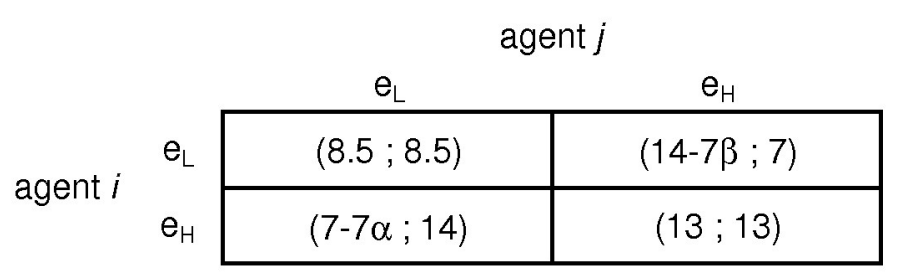

When the relationship is a one-shot, a selfish agent or an inequity averse agent with $\beta<$ $\frac{1}{7} \approx 0.15$ has a dominant strategy that is to play $e_{L}$. Playing $e_{L}$ is the best response to $e_{L}$ and playing $e_{H}$ is the best response to $e_{H}$ for an inequity averse agent with $\beta \geq 0.15$. We must then analyze the case of incomplete information. 
Under incomplete information, we assume that all inequity averse agents play the same effort level and that all selfish agents play their dominant strategy, $e_{L}$. If inequity averse agents have $\beta<0.15$, there is a unique equilibrium in which all the agents play $e_{L}$. However, if inequity averse agents have $\beta \geq 0.15$, the expected utilities of an inequity averse agent is written in the following matrix depending on his effort decision.

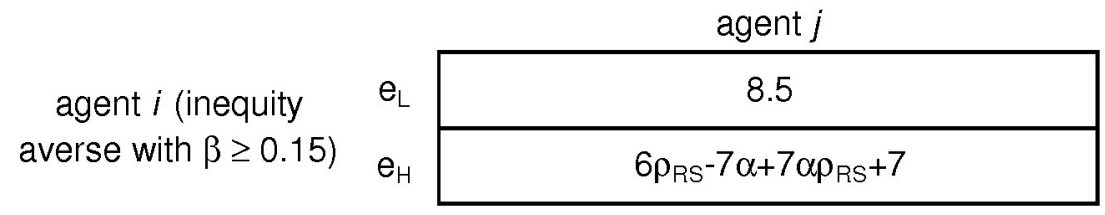

An inequity averse agent with $\beta \geq 0.15$ decides to play the $e_{H}$ effort level if $7 \alpha\left(1-\rho_{R S}\right) \leq$ $6 \rho_{R S}-1.5 \Longleftrightarrow \alpha \leq \frac{6 \rho_{R S}-1.5}{7\left(1-\rho_{R S}\right)}$ with $\rho_{R S} \neq 1$. For $\rho_{R S}=1$, this inequality is always verified $\forall \alpha$. For the following, we call this inequality $\alpha \leq \alpha^{R S}$. Then, if inequity averse agents have $\beta \geq 0.15$ and $\alpha \leq \alpha^{R S}$, there exist two symmetric equilibria, either both agents play $e_{L}$ or both agents play $e_{H}$.

The relationship between agents lasts for five periods.

If inequity averse agents have $\beta<0.15$ or $\alpha>\alpha^{R S}$, all the agents have a dominant strategy that is to play $e_{L}$. To determine the equilibrium in a repeated relationship, we use the trigger strategy (as soon as someone deviates from the Pareto optimum, it is impossible to reach it again latter). We observe that a selfish agent has an interest to play $e_{L}$ only at the fifth period of the relationship. The other agent is aware of this strategy and plays $e_{L}$ at the fourth period. By backward induction, the only equilibrium is that both types of agents play the low effort level at every period when inequity averse agents have $\beta<0.15$ or $\alpha>\alpha^{R S}$.

If inequity averse agents have $\beta \geq 0.15$ and $\alpha \leq \alpha^{R S}$, we must search for the effort decision of selfish agents at the fourth period. Let consider periods 4 and 5 .

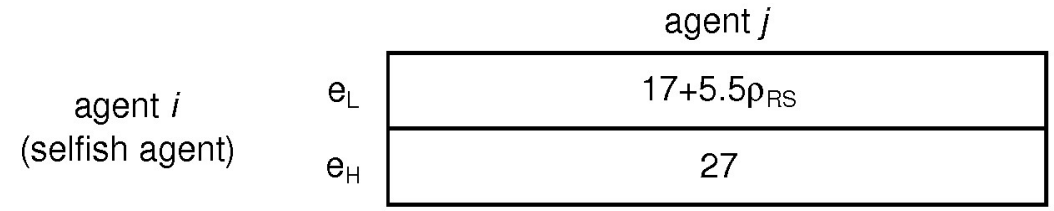

It appears in this case that selfish agents play $e_{H}$ at the fourth period. Two equilibria exist when inequity averse agents have $\beta \geq 0.15$ and $\alpha \leq \alpha^{R S}$. Both types of agents playing $e_{L}$ 
for all the periods of the relationship is an equilibrium. A second equilibrium is such that the selfish agents choose the high effort level for the periods one to four and the low effort level at the fifth period and the inequity averse agents play the high effort level for the five periods of the relationship.

\section{Stage 1 - Choice of payment scheme}

To compute the perfect Bayesian equilibrium of the two-stage game with incomplete information, we assume that all selfish agents are compensated under the competition, $\rho_{C}=0$, and that all inequity averse agents are compensated under the revenue-sharing scheme, $\rho_{R S}=1$. For $\rho_{R S}=1, \alpha \leq \alpha^{R S}$ is always verified $\forall \alpha$. The expected utilities presented are the expected utilities for the whole sequence (for the five periods that compose the relationship between agents). We must find which payment scheme agents choose depending on their inequity aversion degrees.

It appears that a selfish agent prefers to be compensated under the revenue-sharing scheme when inequity averse agents are such that $\beta \geq 0.15$ and $\alpha \leq \alpha^{R S}$. The equilibrium is not separating in this case because all agents, whatever their type, prefer to be compensated under the revenue-sharing scheme. Then, if inequity averse agents want the selfish agents to be compensated under the competition, they must play $e_{H}$ for the four first periods but play $e_{L}$ at the last period. This is the condition to have a separating equilibrium that guaranties selfish agents under the competitive scheme, $\rho_{R S}=1$.

The choices of payment scheme for all the degrees of inequity aversion are then presented in table 9. ${ }^{24}$ However, the no equilibrium cases are very specific. Moreover, under the assumption of a share of inequity averse agents higher than $40 \%$, some cases do not exist. So, we present the theoretical predictions under this assumption in the core of the text. The avoided cases being very rare, we do not think losing too much information by making this assumption. What is important to notice is that inequity averse agents choose the revenue-sharing payment scheme if $\alpha \geq \frac{2.7-6.3 \beta}{4.9}$. We write this inequality $\alpha \geq \alpha^{S}$. Inequity averse agents with $\beta \geq 0.15$ choose the revenue-sharing scheme as well.

Selfish agents and inequity averse agents with low $\alpha$ and low $\beta$ prefer the competition while inequity averse agents with either high $\alpha$ or high $\beta$ prefer the revenue-sharing scheme.

\footnotetext{
${ }^{24}$ What we call "inexistant cases" are cases in which the different conditions on $\alpha$ and $\beta$ are not compatible. When it is written that there exist no equilibrium, it means that these agents prefer the competition when only selfish agents are under the competition but prefer the revenue-sharing scheme when both selfish and inequity averse agents are under the competition.
} 


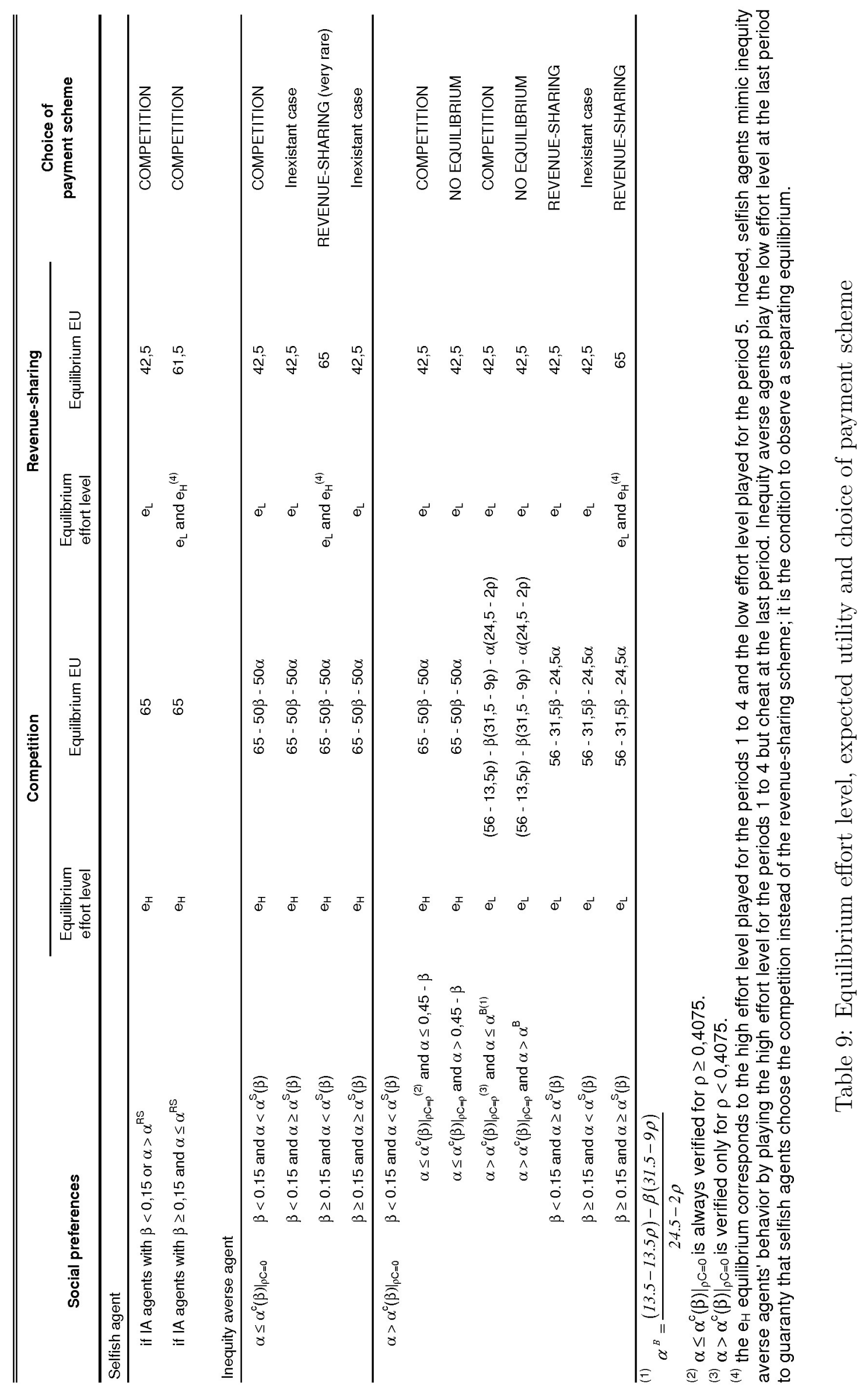

